\title{
Neurochemical and Histologic Characterization of Striatal Excitotoxic Lesions Produced by the Mitochondrial Toxin 3-Nitropropionic Acid
}

\author{
M. Flint Beal, ${ }^{1,2}$ Emmanuel Brouillet, ${ }^{1,2}$ Bruce G. Jenkins, ${ }^{3,4}$ Robert J. Ferrante, ${ }^{5}$ Neil W. Kowall, ${ }^{2}$ Joanne M. \\ Miller, ${ }^{1,2}$ Elsdon Storey, ${ }^{1,2}$ Rachana Srivastava, ${ }^{1,2}$ Bruce R. Rosen, ${ }^{3,4}$ and Bradley T. Hyman ${ }^{1,2}$ \\ ${ }^{1}$ Neurochemistry Laboratory, ${ }^{2}$ Neurology Service, ${ }^{3} \mathrm{MGH}-\mathrm{NMR}$ Center, ${ }^{4}$ Department of Radiology, and ${ }^{5}$ Department of \\ Pathology, Massachusetts General Hospital and Harvard Medical School, Boston, Massachusetts 02114
}

An impairment of energy metabolism may underlie slow excitotoxic neuronal death in neurodegenerative diseases. We therefore examined the effects of intrastriatal, subacute systemic, or chronic systemic administration of the mitochondrial toxin 3-nitropropionic acid (3-NP) in rats. Following intrastriatal injection 3-NP produced dose-dependent striatal lesions. Neurochemical and histologic evaluation showed that markers of both spiny projection neurons (GABA, substance $P$, calbindin) and aspiny interneurons (somatostatin, neuropeptide Y, NADPH-diaphorase) were equally affected. Subacute systemic administration of 3-NP produced agedependent bilateral striatal lesions with a similar neurochemical profile. However, in contrast to the intrastriatal injections, striatal dopaminergic afferent projections were spared. Both freeze-clamp measurements and chemical shift magnetic resonance spectroscopy showed that 3-NP impairs energy metabolism in the striatum in vivo. Microdialysis showed no increase in extracellular glutamate concentrations after systemic administration of 3-NP. The lesions produced by intrastriatal injection or systemic administration of 3-NP were blocked by prior decortication. However, the NMDA antagonist MK- 801 did not block the effects of intrastriatal 3-NP, consistent with a non-NMDA excitotoxic mechanism. In contrast to subacute systemic administration of 3-NP, chronic (1 month) administration produced lesions confined to the striatum in which there was relative sparing of NADPHdiaphorase interneurons, consistent with an NMDA excitotoxic process. Chronic administration showed growth-related proliferative changes in dendrites of spiny neurons similar to changes in Huntington's disease (HD). These results are consistent with in vitro studies showing that mild metabolic compromise can selectively activate NMDA receptors while more severe compromise activates both NMDA and nonNMDA receptors. Chronic administration of 3-NP over 1 month produces selective striatal lesions that replicate many of the characteristic histologic and neurochemical features of HD.

[Key words: mitochondria, excitotoxicity, Huntington's disease, striatum, magnetic resonance spectroscopy]

Received Jan. 8, 1993; revised Apr. 6, 1993; accepted Apr. 13, 1993.

This work was supported by NINDS Grants 16367 and NS 10828 and the Hereditary Disease Foundation. E.B. is a postdoctoral fellow of the Fyssen Foundation. R.S. is a summer fellow of the Parkinson's Disease Foundation. We thank Sharon Melanson for typing the manuscript, and Usha McGarvey for technical assistance.

Correspondence should be addressed to Dr. M. Flint Beal, Warren 408, Massachusetts General Hospital, Boston, MA 02114.

Copyright (C) 1993 Society for Neuroscience $0270-6474 / 93 / 134181-12 \$ 05.00 / 0$
A large number of studies now suggest that excitatory amino acids play a role in the mechanism of neuronal death in several diseases. Experimental studies in both ischemia and hypoglycemia have shown that there are dramatic increases in extracellular glutamate, and that neuronal death can be blocked by excitatory amino acid antagonists (Choi, 1988). The role of excitotoxic mechanisms in neurodegenerative diseases is more speculative. In these illnesses one has to account for gradually evolving relentless cell death that can progress over 10 or more years. These illnesses, such as Alzheimer's disease, Parkinson's disease, and Huntington's disease (HD), are characterized by circumscribed and selective neuronal death.

One possibility is that a progressive impairment of energy metabolism may secondarily result in slow excitotoxic neuronal death (Albin and Greenamyre, 1992; Beal, 1992). Disruption of ATP synthesis may lead to partial neuronal depolarization with activation of voltage-dependent NMDA receptors and secondary excitotoxic neuronal damage (Novelli et al., 1988). We have been particularly intrigued by the possibility that this mechanism might underlie neuronal degeneration in HD. Several studies have reported decreased glucose metabolism and abnormalities in mitochondrial electron transport enzymes in HD (reviewed in Beal, 1992). We have recently obtained the first in vivo evidence of impaired oxidative energy metabolism in HD by demonstrating increased concentrations of lactate in cerebral cortex using nuclear magnetic resonance spectroscopy (Koroshetz et al., 1992). In addition, studies in both rodents and primates show striking similarities between striatal lesions induced by NMDA agonists and the neurochemical and histologic features of HD (Beal, 1992; Ferrante et al., 1993). Further evidence in support of an NMDA excitotoxic mechanism in $\mathrm{HD}$ is the finding of a preferential loss of striatal NMDA receptors (Young et al., 1988), although a latter study showed depletion of both NMDA and non-NMDA receptors (Dure et al., 1991).

We therefore examined the mechanism of neuronal degeneration produced by the known mitochondrial toxin 3-nitropropionic acid (3-NP). 3-NP is an irreversible inhibitor of succinate dehydrogenase that inhibits both the Krebs cycle and complex II of the mitochondrial electron transport chain (Alston et al., 1977; Coles et al., 1979). It is of particular interest since 3-NP produces selective basal ganglia lesions and delayed dystonia when accidently ingested in human (Ludolph et al., 1991). In the present study we examined the neurochemical and histologic effects of both intrastriatal and systemic administration of 3-NP. We also determined its effects on energy metab- 
olism using both in vivo water-suppressed proton chemical shift magnetic resonance imaging techniques, and direct measurements of ATP and lactate using the freeze-clamp technique. To determine whether lesions were caused by an excitotoxic mechanism, we examined the effects of prior decortication, which removes the corticostriatal glutamatergic input, as well as the effects of treatment with the noncompetitive NMDA antagonist MK-801. Last we examined whether chronic administration over 1 month could produce slow progressive neuronal degeneration showing the neuronal selectivity and neurochemical features of HD.

\section{Materials and Methods}

Male Sprague-Dawley rats (Charles River, Cambridge, MA) weighing 175-200 gm were anesthetized with pentobarbital $(50 \mathrm{mg} / \mathrm{kg}$, i.p.). 3-NP (Aldrich, Milwaukee, WI) was dissolved in water and the $\mathrm{pH}$ adjusted to 7.4 with $\mathrm{NaOH}$. Intrastriatal injections of varying doses were made in the left striatum in a volume of $1 \mu 1$ using a blunt-tipped 30 gauge Hamilton syringe (Beal et al., 1989, 1991). All injections were made over $1 \mathrm{~min}$ and the needle was left in place for $1 \mathrm{~min}$ before being slowly withdrawn. Nine to 10 animals were examined in each group. Prior decortication was performed by removing frontoparietal cortex by gentle suction 1 week before the intrastriatal injections. Hemostasis was achieved with Gelfoam. To examine the effects of MK-801 on 3-NP lesions, animals were administered MK- $801(5 \mathrm{mg} / \mathrm{kg}$, i.p.) or saline $30 \mathrm{~min}$ before injection and then for every $4 \mathrm{hr}$ for $24 \mathrm{hr}$.

Subacute systemic administration of 3-NP was made at a dose of 20 $\mathrm{mg} / \mathrm{kg}$ subcutaneously by Alzet pump for $5 \mathrm{~d}$. Both 1 - and 4-monthold animals were examined. 3-NP was made up in water at $20 \mathrm{mg} / \mathrm{kg} /$ $\mathrm{ml}$ and adjusted to $\mathrm{pH} \mathrm{7.4}$. For chronic administration 20 rats aged 12 months were treated with $3-\mathrm{NP}$ for 1 month at a dose of $12 \mathrm{mg} / \mathrm{kg} / \mathrm{d}$ by subcutaneous Alzet pump (Alzet Corp., Palo Alto, CA). Six controls received normal saline. In the case of the MK-801 experiment, animals were killed at $24 \mathrm{hr}$. Following intrastriatal administration of 3-NP animals were killed at 1 week. In the experiments in which animals received subacute 3 -NP by Alzet pump, the pump was removed when animals were acutely ill (5-7 d), and the animals were then killed. The 12 -month-old animals treated with $12 \mathrm{mg} / \mathrm{kg} / \mathrm{d}$ of 3-NP for 1 month by Alzet pump were killed 1 week following the 3-NP administration. Only half the animals treated at this dosage survived 1 month. The remaining animals became acutely ill after $1-2$ weeks and had to be killed at this time point. These animals showed large lesions.

For neurochemical analysis the left and right striata were rapidly dissected from a $2-\mathrm{mm}$-thick slice on a chilled glass plate as previously described (Beal et al., 1989, 1991). Tissue samples were sonicated, extracted, and assayed for somatostatin-like immunoreactivity (SLI), neuropeptide Y-like immunoreactivity (NPYLI), and substance P-like immunoreactivity (SPLI) as reported previously (Arnold et al., 1982; Beal et al., 1986b; Beal and Mazurek, 1987). GABA was measured by HPLC with electrochemical detection (Ellison et al., 1987). Monoamines and their metabolites were quantified by HPLC with 16-electrode electrochemical detection (Beal et al., 1990). Protein was measured with a fluorometric assay (Bohlen et al., 1973).

The effects of intrastriatal injections of 3-NP on ATP and lactate concentrations were examined using the freeze-clamp procedure and focused microwave irradiation for $0.6 \mathrm{sec}$ at $5.4 \mathrm{~kW}$. Six $1-2$-monthold animals in each group were examined at $3 \mathrm{hr}$ after intrastriatal injection of saline or $1000 \mathrm{nmol}$ of 3-NP. In addition, the effects of systemic administration of $30 \mathrm{mg} / \mathrm{kg}$ of $3-\mathrm{NP}$ intraperitoneally to 4-month-old animals were examined at $4 \mathrm{hr}$. ATP was measured by the luciferin-luciferase assay (Lust et al., 1981) and lactate was measured with an enzymatic assay (Schon, 1965).

The effects of systemic administration of 3-NP on striatal extracellular concentrations of glutamate were examined using the microdialysis technique. Male Sprague-Dawley rats (250-350 gm) were anesthetized with pentobarbital $(50 \mathrm{mg} / \mathrm{kg}$, i.p.) on the day of surgery and placed in a Kopf stereotaxic frame. Stainless steel guide shafts (21 gauge tubing) were implanted in the striatum and secured with dental cement. Animals were allowed to recover for $24 \mathrm{hr}$ before probe insertion. Probes of concentric design ( $4 \mathrm{~mm}$ exposed membrane; $6000 \mathrm{MW}$ cutofl) were perfused with modified Ringer's solution containing $2.7 \mathrm{~mm} \mathrm{~K}{ }^{+}, 145$ $\mathrm{mM} \mathrm{Na}^{+}, 1.2 \mathrm{mM} \mathrm{Ca}^{2+}, 1.0 \mathrm{~mm} \mathrm{Mg}^{2+}$, and $2 \mathrm{~mm}$ phosphate, $\mathrm{pH} 7.40$, at a flow rate of $2.0 \mu \mathrm{l} / \mathrm{min}$ using a CMA/100 microinjection pump; samples were collected at 20 min intervals. Three animals in each group were treated with either $3-\mathrm{NP}$ at a dose of $30 \mathrm{mg} / \mathrm{kg}$ intraperitoneally or normal saline. Samples were collected for $5 \mathrm{hr}$. Glutamate concentrations in the dialysates were measured by HPLC with electrochemical detection (Ellison et al., 1987).

The ability of both local and systemic administration of 3-NP to induce impairment of oxidative metabolism was evaluated in real time with water-suppressed proton chemical shift magnetic resonance imaging (Jenkins et al., 1991). 3-NP was administered at a dose of $40 \mathrm{mg}$ / $\mathrm{kg}$ for $2 \mathrm{~d}$ to 1 -month-old rats. Rats were imaged at $4.7 \mathrm{~T}$ using a GE Omega CSI imager with a $30 \mathrm{~mm}$ bird cage coil using a double-phase encode technique with a binomial refocusing pulse. Slice thickness was $8 \mathrm{~mm}$. Phase encoding was performed in two dimensions to give a three-dimensional data set. The entire echo was collected using a TR of $2.15 \mathrm{sec}$ and TE of $272 \mathrm{msec}$ with an inversion pulse for lipid suppression ( $\mathrm{TI}=210 \mathrm{msec}$ ), eight averages, and the field of view was 50 $\times 50 \mathrm{~mm}$ with $16 \times 16$ phase-encoding steps. A two-dimensional image of lactate was obtained. The parameters for the water images were TR/ $\mathrm{TE}=3200 / 80 \mathrm{msec}$, with a slice thickness of $2.5 \mathrm{~mm}$.

For histologic evaluation animals were deeply anesthetized 1 week after lesioning and perfused with ice-cold saline, followed by phosphatebuffered 4\% paraformaldehyde (Beal et al., 1989, 1991). Brains were sectioned at $50 \mu \mathrm{M}$ intervals on a freezing microtome. Sections were stained for Nissl substance using cresyl violet or examined using NADPHdiaphorase histochemistry. Combined staining for Nissl substance and NADPH-diaphorase was performed on select sections. Some sections were also stained immunohistochemically for calcium-binding protein (CaBP), somatostatin, or glial fibrillary acidic protein (GFAP), and neuronal cell adhesion molecule (NCAM) using a previously described methodology (Beal et al., 1989, 1991). Golgi studies were carried out as previously described (Ferrante et al., 1991). Quantitation of striatal neurons in combined Nissl/NADPH-diaphorase-stained sections from both 3-NP- and saline-treated animals was carried out in $350 \times 500$ $\mu \mathrm{m}$ fields centered around the lesions at a magnification of $400 \times$, using an eyepiece graticule. Six to eight counts were made in each animal, and were averaged. Counts were expressed as the ratio of NADPHdiaphorase positive neurons to total Nissl-stained neurons. The results are expressed as the mean \pm SEM.

Neurochemical measurements on the lesioned side were compared with those on the unlesioned (control) side and expressed as percentages of control values. The unlesioned sides did not differ from saline-injected controls (Beal et al., 1989, 1991). The results are expressed as mean \pm SEM values. Both neurochemical and histologic comparisons were made using Student's $t$ test (two tailed) or one-way analysis of variance.

\section{Results}

The effects of increasing doses of intrastriatal injections of 3-NP on striatal neurochemical markers are shown in Figure 1. There were dose-dependent decreases in GABA, SPLI, dopamine, 3,4dihydroxyphenylacetic acid (DOPAC), and homovanillic acid (HVA). Dopamine was depleted to a greater extent than the other neurochemical markers. SLI and NPYLI were also significantly $(P<0.01)$ depleted to $61.5 \pm 13.6 \%$ and $63.7 \pm$ $11.9 \%$ of control following a dose of $500 \mathrm{nmol}$ of $3-\mathrm{NP}$. Prior decortication significantly protected against decreases in GABA, SPLI, dopamine, and DOPAC; however, the effects on dopamine and DOPAC were only partial. The effects of MK-801 on lesions induced by intrastriatal injections of $500 \mathrm{nmol}$ of 3-NP at $24 \mathrm{hr}$ are shown in Figure 2. There was no significant protective effect.

The neurochemical effects of subacute systemic administration of 3-NP at a dose of $20 \mathrm{mg} / \mathrm{kg} / \mathrm{d}$ by Alzet pump in 1 - and 4-month-old animals are shown in Figure 3. Controls received normal saline and measurements are expressed as percentage of control. There were no significant effects in 1-month-old animals. The 4-month-old animals, however, showed significant $25 \%$ depletions of GABA, substance $P$, somatostatin, and neuropeptide $\mathrm{Y}$. Dopamine and 5-HT concentrations were spared 


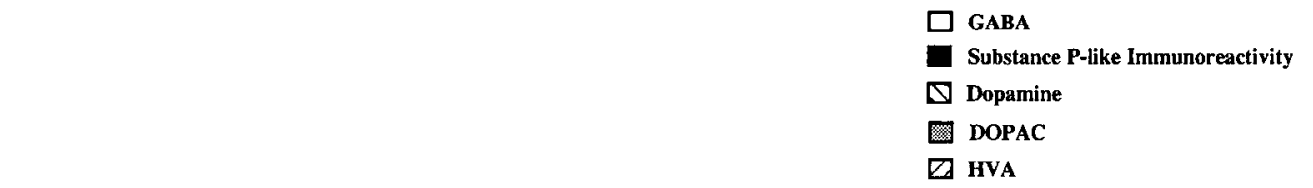

Figure 1. Neurochemical effects of intrastriatal injection of increasing doses of 3-NP, and the effect of prior decortication. Neurochemical measurements were compared with those of the unlesioned (control) contralateral striatum and expressed as percentage of control \pm SEM. ${ }^{*}, P<0.05 ;{ }^{* *}, P<0.01 ;{ }^{* * *}$, $P<0.001$. but there were significant increases in DOPAC and HVA, consistent with increased dopamine turnover.

The effects of local injection of $1000 \mathrm{nmol}$ of 3-NP on ATP and lactate concentrations at $3 \mathrm{hr}$ were examined using the freeze-clamp technique. There was a significant $(P<0.01)$ decrease in ATP to $45.9 \pm 14.2 \%$ of control and a significant $(P$ $<0.001$ ) threefold increase in lactate to $300 \pm 13 \%$ of control. ATP concentrations in controls were $14.2 \pm 0.4 \mathrm{nmol} / \mathrm{mg}$ protein and lactate concentrations were $0.016 \pm 0.002 \mu \mathrm{mol} / \mathrm{mg}$ of protein. Focused microwave irradiation confirmed a significant $(P<0.01)$ increase in lactate to $289 \pm 14 \%$ of control at $3 \mathrm{hr}$. Four hours after systemic administration of 3-NP $(30 \mathrm{mg} /$ $\mathrm{kg}$, i.p.), there were significant $(P<0.05)$ increases in lactate concentrations in the striatum as compared with saline controls $(203 \pm 19 \%)$, but there were no significant changes in the cerebral cortex, hippocampus, and cerebellum.

Two-dimensional lactate imaging using water-suppressed chemical shift magnetic resonance imaging confirmed a focal increase in lactate at the injection site $3 \mathrm{hr}$ after injection of
3-NP. $\mathrm{T}_{2}$-weighted imaging showed increased signal in the striatum following local administration of 3-NP. Following systemic administration of 3-NP at a dose of $40 \mathrm{mg} / \mathrm{kg} / \mathrm{d}$ intraperitoneally in 1-month-old animals, focal increases in lactate concentrations were seen over both striata at $2 \mathrm{~d}$ (Fig. 4). Lactate concentration estimates in four different animals were $1.59 \pm 0.25 \mathrm{~mm}$ in the left striatum and $1.62 \pm 0.28 \mathrm{~mm}$ (mean \pm SD) in the right striatum. These values are two- to threefold above baseline levels. In most cases lactate signal intensity preceded the development of lesions on $\mathrm{T}_{2}$-weighted scans in animals treated with systemic injections. Similar results were obtained with a dose of $20 \mathrm{mg} / \mathrm{kg} / \mathrm{d}$ in $4-$ month-old animals.

Microdialysis studies were carried out to determine if 3-NP results in striatal glutamate release. Samples were collected for $20 \mathrm{~min}$ intervals following intraperitoneal administration of 30 $\mathrm{mg} / \mathrm{kg}$ of 3-NP. Administration of this dose of 3-NP resulted in no significant alterations in striatal glutamate concentrations as compared with controls who received normal saline (Fig. 5). Systemic administration of the same dose of $3-\mathrm{NP}(30 \mathrm{mg} / \mathrm{kg}$,

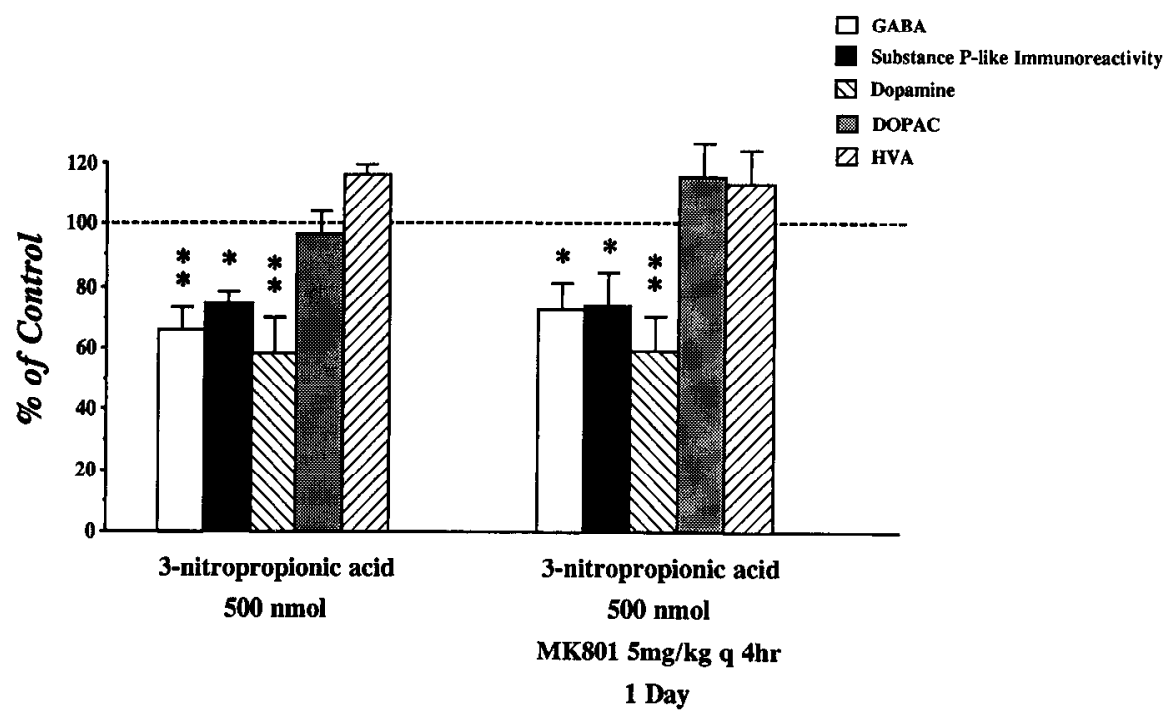

Figure 2. Effects of MK-801 treatment on GABA, substance $P$, and dopamine and its metabolites at $24 \mathrm{hr}$. MK-801 showed no protective effects against 3-NP lesions at $24 \mathrm{hr} .{ }^{*}, P<$ 0.05 ; ** $P<0.01$; as compared with the control side. 


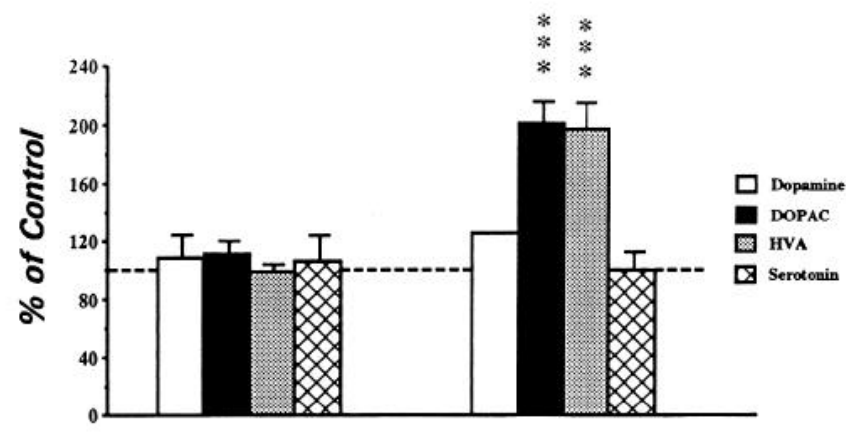

Figure 3. Neurochemical effects of systemic administration of $3-\mathrm{NP}$, at 20 $\mathrm{mg} / \mathrm{kg} / \mathrm{d}$, or saline to 1 - and 4-monthold rats for $5 \mathrm{~d}$ by subcutaneous Alzet pump. Neurochemical measurements are expressed as percentage of control \pm SEM. Comparisons were made by nonpaired Student's $t$ test in each group. As compared with saline controls there were no significant effects in 1-monthold animals. In 4-month-old animals there were significant depletions in markers of striatal neurons and significant increases in dopamine metabolites, but no significant effect on dopamine and 5-HT. ${ }^{* *}, P<0.01{ }^{* * *}, P<$ 0.001

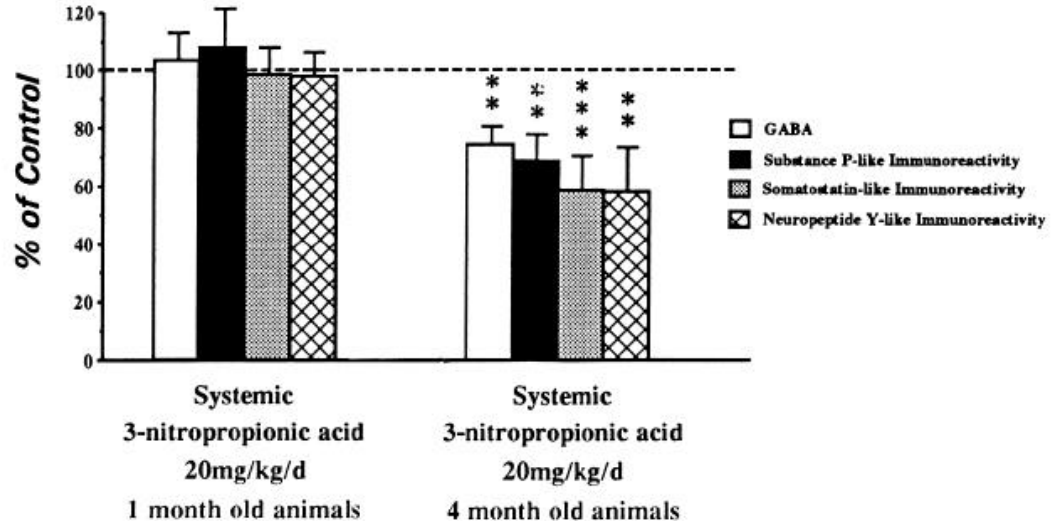

i.p.) to 4-month-old rats resulted in a significant twofold increase in lactate at $4 \mathrm{hr}$ in the striatum using the freeze-clamp method, but no change in cerebral cortex, hippocampus, or cerebellum (data not shown). The striatal lactate concentrations in the 3-NPtreated animals were $0.042 \pm 0.013 \mu \mathrm{mol} / \mathrm{mg}$ of protein versus $0.017 \pm 0.004 \mu \mathrm{mol} / \mathrm{mg}$ of protein in controls $(P<0.05, n=$ $6)$.
Histologic examination of 4-month-old rats injected with 500 nmol of 3-NP $(n=4)$ showed extensive neuronal loss and gliosis, which was confirmed by GFAP staining. There was sparing of some large neurons at the lesion site, but NADPH-diaphorase staining and $\mathrm{CaBP}$ showed a comparable neuronal loss throughout the lesioned area. Examination of rats that received subacute systemic administration of 3-NP at a dose of $20 \mathrm{mg} / \mathrm{kg} / \mathrm{d}$ in-

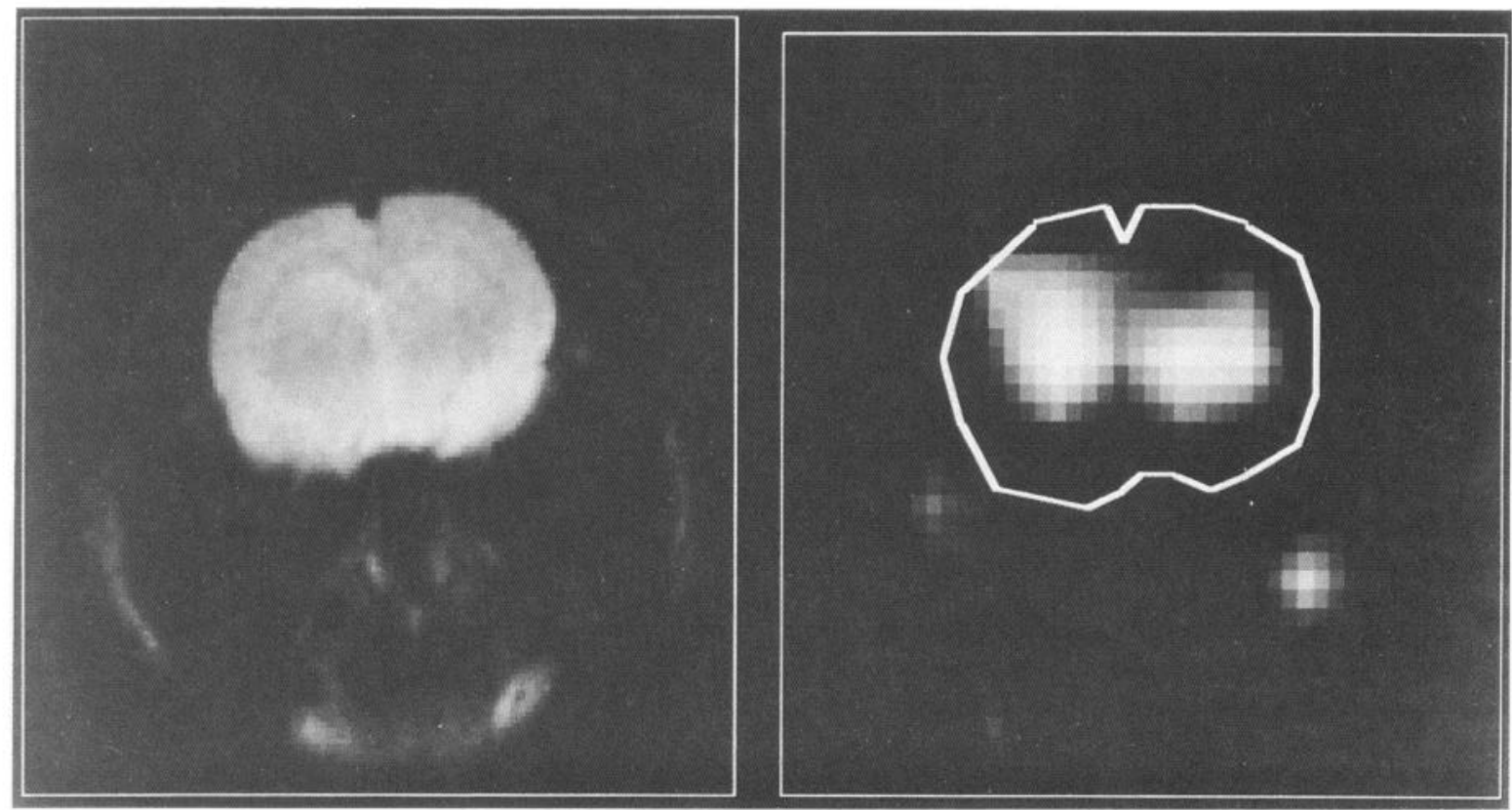

Figure 4. Water-suppressed chemical shift magnetic resonance imaging (TE/TR of 272/2100 msec) following systemic administration of 3-NP to a 1 -month-old rat for $3 \mathrm{~d}$ at a dose of $40 \mathrm{mg} / \mathrm{kg}$. There is essentially no increase in $\mathrm{T}_{2}$-weighted water signal in the striata (left) at a time in which there are focal lactate accumulations in the striata (right). 


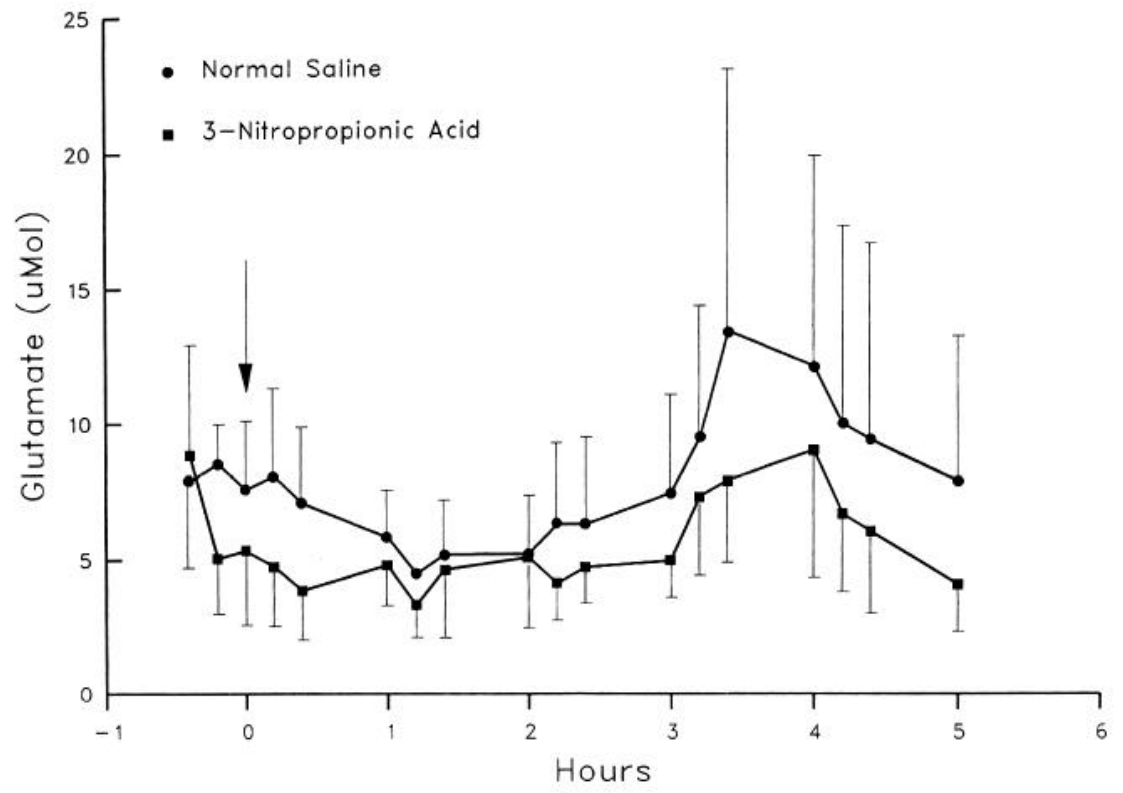

Figure 5. Glutamate concentrations in striatal dialysate after intraperitoneal injection of $30 \mathrm{mg} / \mathrm{kg}$ of $3-\mathrm{NP}$ or normal saline. As compared with normal saline, there were no significant increases in glutamate concentrations at any time point over $5 \mathrm{hr}$. traperitoneally for five $\mathrm{d}(n=5)$ showed bilateral striatal lesions. Nissl stains showed loss of neurons and gliosis that was confirmed by GFAP staining (Fig. 6). There was a depletion of both somatostatin-immunoreactive and NADPH-diaphorase neurons within the lesioned striata, with no selective sparing relative to the loss of CaBP neurons. In some animals that recerved subacute administration of $3-\mathrm{NP}$, there was gliosis and neuronal loss in area CA1 of the hippocampus in addition to striatal lesions (Fig. 7).

Following subacute administration of 3-NP, animals devel-

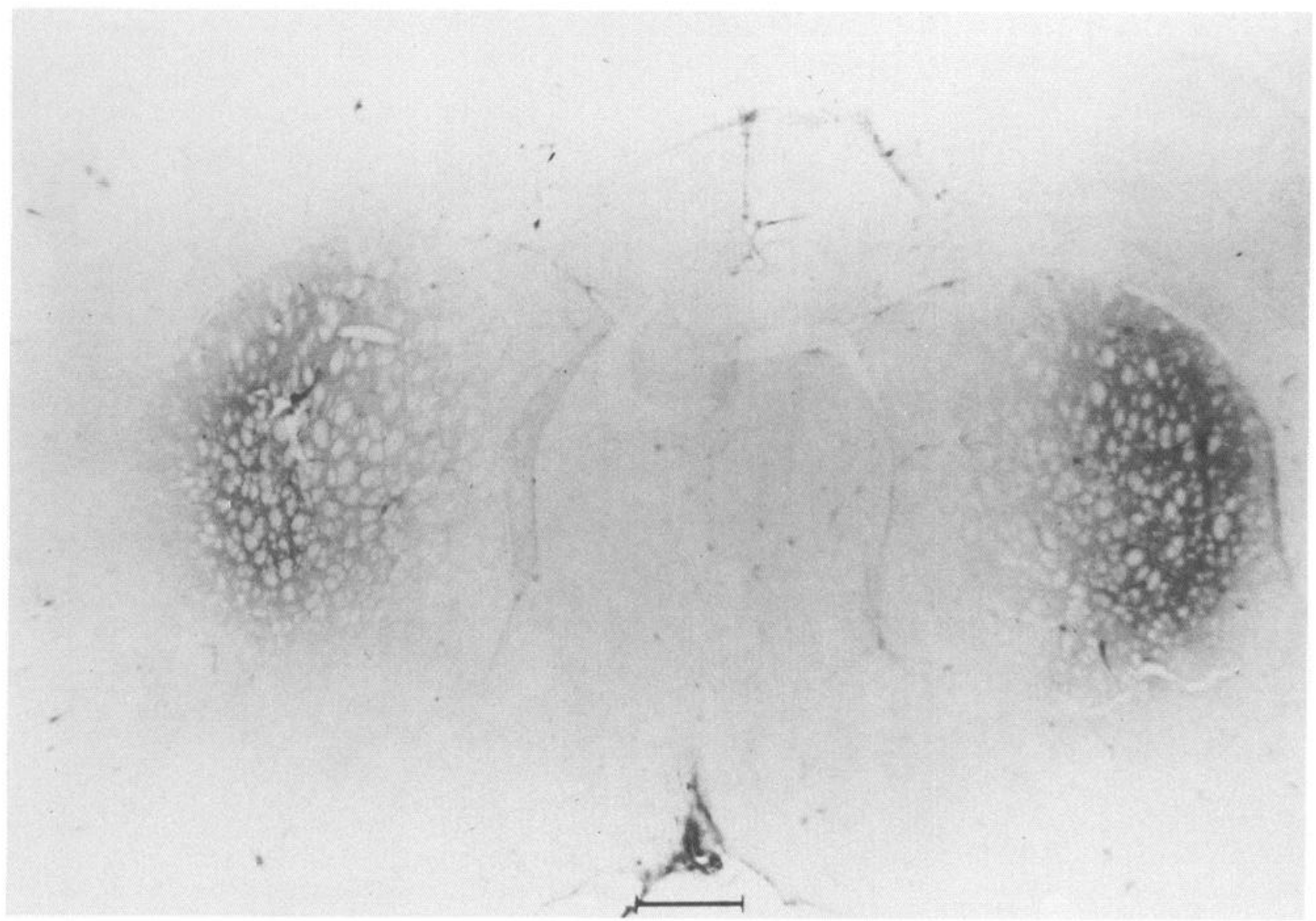

Figure 6. GFAP-stained section at the level of the anterior striatum following subacute systemic administration of 3-NP. Focal increases in GFAP staining are seen in the dorsolateral striatum bilaterally. 
Figure 7. GFAP-stained section of the hippocampus following subacute systemic administration of 3-NP. There is a focal increase in GFAP staining in the hippocampus that is particularly marked in the CAl field.

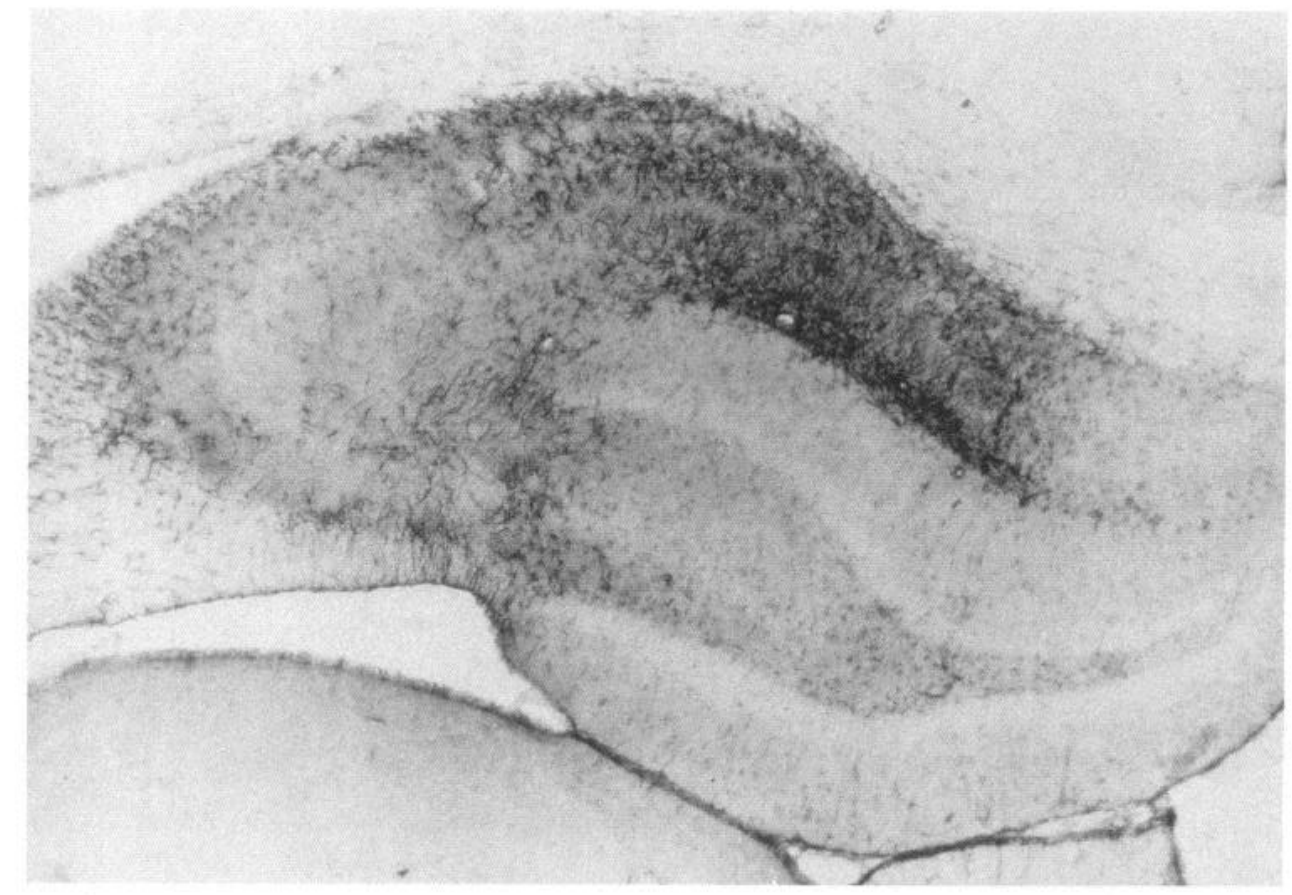

oped dystonic posturing in the posterior extremities. This was characterized by slowing of movements that, when severe, resulted in animals being unable to move the posterior extremities, and dragging themselves forward using the forelimbs. In its most

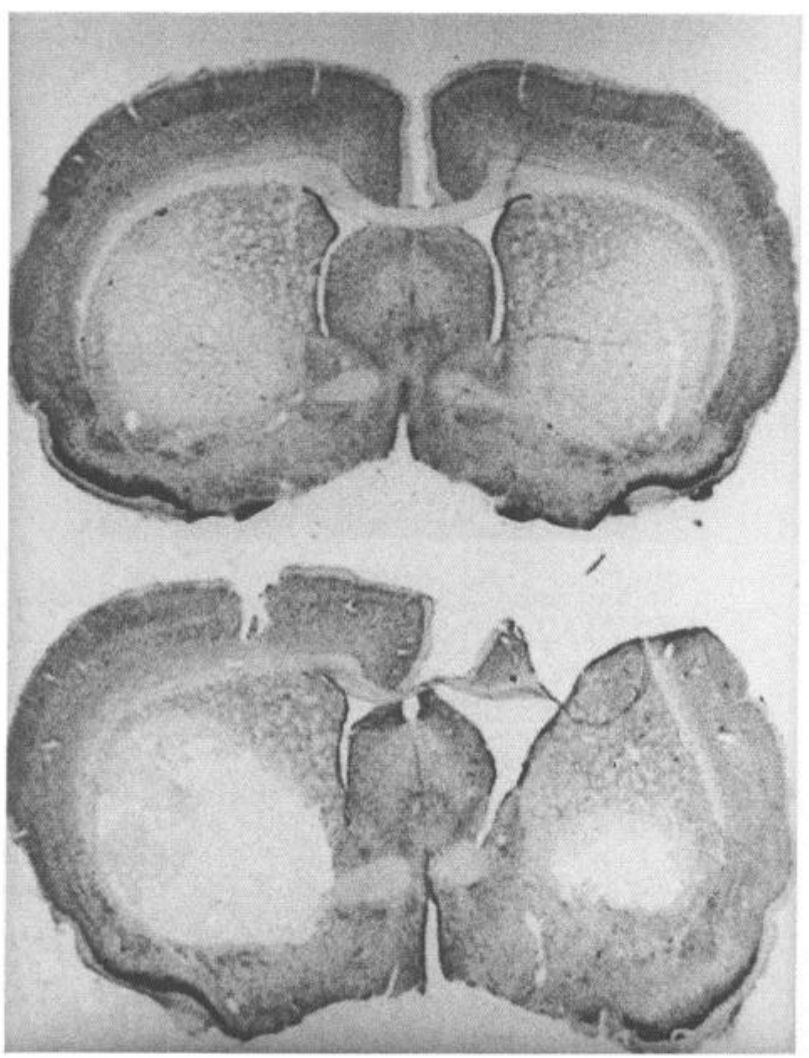

Figure 8. Effects of prior decortication on lesions induced by subacute systemic administration of 3-NP. On Nissl-stained sections large bilateral lesions are seen as pale staining in the striatum (top), which is significantly attenuated on the side with prior decortication (bottom). extreme form animals became "recumbent,"lying on their sides. If they were fed and allowed to drink in this state they would subsequently improve and in some cases recover the ability to ambulate independently. However, survival was not greater than $50-60 \%$. The dystonic posturing and rigidity appears to be related to the basal ganglia lesions since examination of the brainstem and spinal cord in three animals showing the movement disorder showed no neuropathologic abnormalities (data not shown).

Histologic evaluation following administration of MK-801 at a dose of $1 \mathrm{mg} / \mathrm{kg} / \mathrm{hr}$ for $24 \mathrm{hr}$ by Alzet pump following a loading intraperitoneal dose of $5 \mathrm{mg} / \mathrm{kg}$ produced no neuroprotective effects as compared with saline following local striatal injection of $500 \mathrm{nmol}$ of $3-\mathrm{NP}$ ( $n=3$ in each group). The effects of prior decortication were examined in 1-month-old rats that received intraperitoneal $3-\mathrm{NP}$ at $30 \mathrm{mg} / \mathrm{kg} / \mathrm{d}$ for $5 \mathrm{~d}(n=3)$ or $7 \mathrm{~d}(n=$ 3). Both Nissl and GFAP stains showed that the lesion on the side with the prior decortication was markedly attenuated. At the site of the maximal lesion, the area of the Nissl-stained lesion on the side with prior decortication was $0.1 \pm 0.1 \mathrm{~mm}^{2}$, which was significantly $(P<0.05)$ less than that on the side with intact cortex, $1.7 \pm 0.6 \mathrm{~mm}^{2}(n=3)$ (Fig. 8).

Chronic administration of 3-NP at a dose of $12 \mathrm{mg} / \mathrm{kg} / \mathrm{d}$ for 1 month in 12-month-old rats produced selective bilateral lesions in the rostrolateral aspect of the caudate putamen in 11 animals. Histopathology was not observed elsewhere in the brains of these animals. The lesions were small $(0.5-2.0 \mathrm{~mm}$ in diameter) and were variable between animals (Fig. 9A). In contrast to intrastriatal and subacute administration of 3-NP, the chronic administration of 3-NP resulted in histopathologic striatal sequelae characterized by a selective sparing of aspiny NADPHdiaphorase neurons concomitant with marked neuronal loss and astrogliosis (Fig. 9B,C). Neuronal counts within the striatum showed a statistically significant reduction in the density of Nisslstained neurons (Table 1). The density of NADPH-diaphorase neurons was increased in the chronically 3-NP-treated animals, although the difference did not show significance. The ratio of 


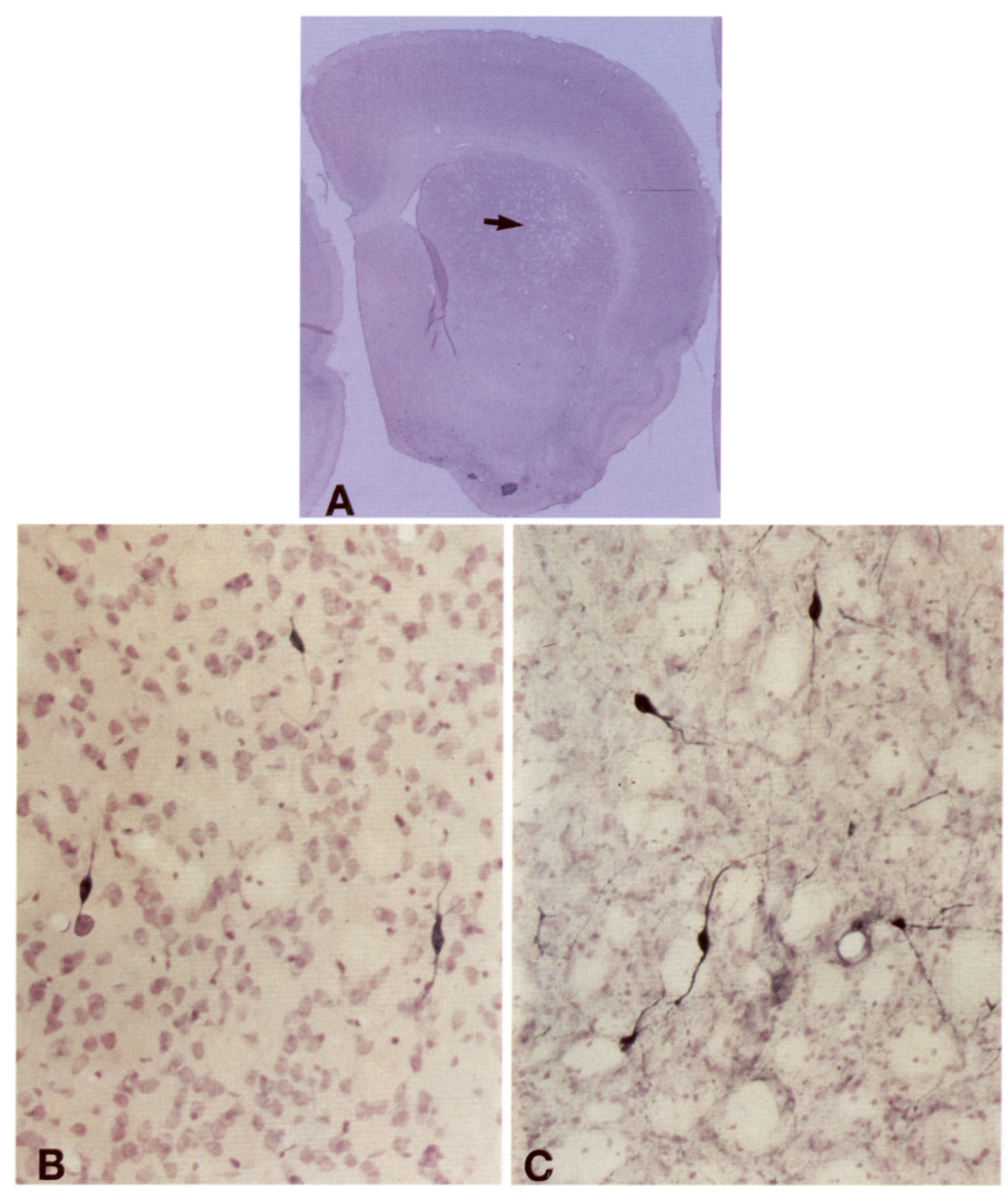

Figure 9. Chronic administration of 3-NP at a dose of $12 \mathrm{mg} / \mathrm{kg} / \mathrm{d}$ produced selective striatal lesions within the rat caudate putamen. A small lesion in the dorsolateral caudate putamen can be identified in $A$, where there is an increased density of white matter bundles (arrow). These lesions were characterized by marked neuronal loss and gliosis with selective preservation of NADPH-diaphorase neurons in $C$ as compared to a salinetreated control in $B$.

NADPH-diaphorase to Nissl neurons, however, was significantly increased, demonstrating a relative sparing of NADPHdiaphorase neurons. Two of the 11 animals did not show any grossly discernable lesion. Quantitative analysis of striatal neurons in these two animals, however, identified a statistically significant loss of Nissl-stained neurons with a sparing of NADPH-diaphorase aspiny neurons (NADPH-diaphorase neurons, $5.7 \pm 0.8 / \mathrm{mm}^{2}$; Nissl neurons, $145 \pm 7.4$; density ratio, 3.9; $P<0.05$ ) (Table 1) as compared with controls. Both of these animals were included in the overall statistical analysis.

In addition, growth-related dysmorphic alterations observed
Table 1. Striatal NADPH-diaphorase and Nissl neuronal counts in chronic 3-NP-treated rats

\begin{tabular}{llcl} 
& $\begin{array}{l}\text { NADPH- } \\
\text { diaphorase }\end{array}$ & Nissl & Density ratio \\
\hline 3-NP lesion & $5.8 \pm 0.8$ & $77.3 \pm 14.2^{* *}$ & $9.3 \% * *$ \\
Control & $5.6 \pm 1.1$ & $196.4 \pm 9.6$ & $2.8 \%$
\end{tabular}

Eleven animals were examined with 3-NP and six saline-treated controls. Data are means \pm SEM

${ }^{* *} p<0.001$. 


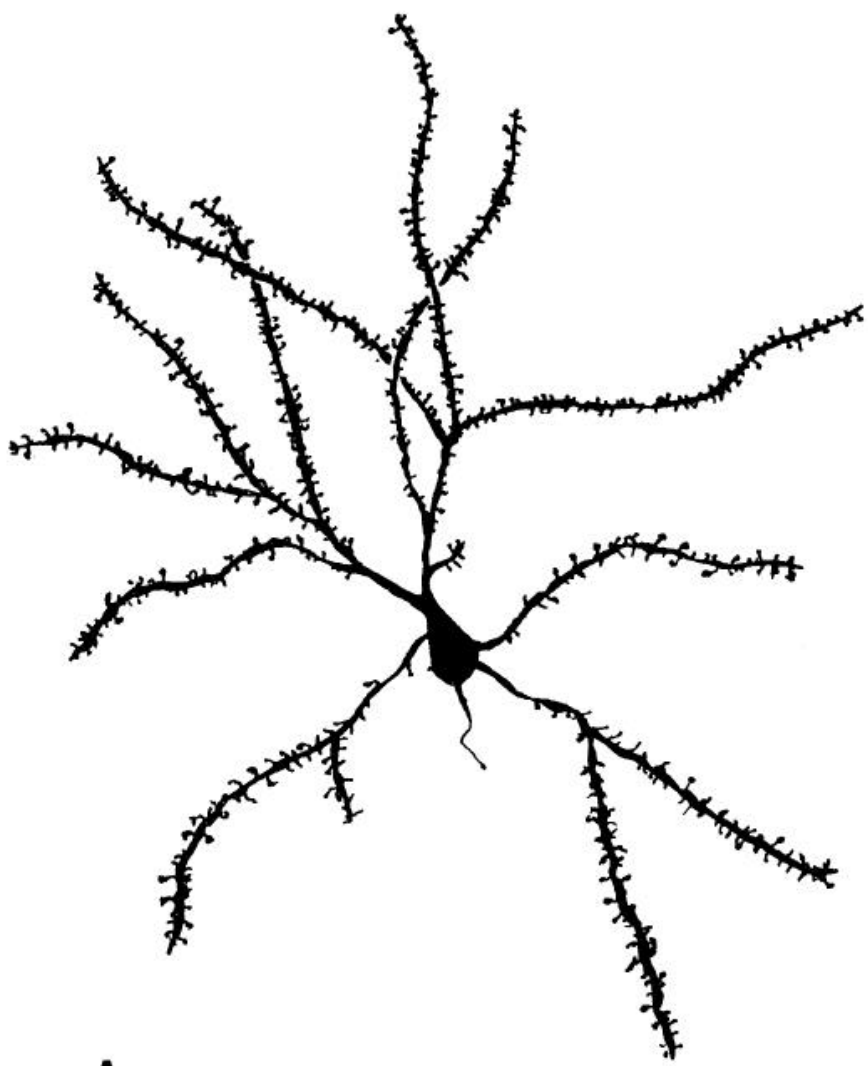

A

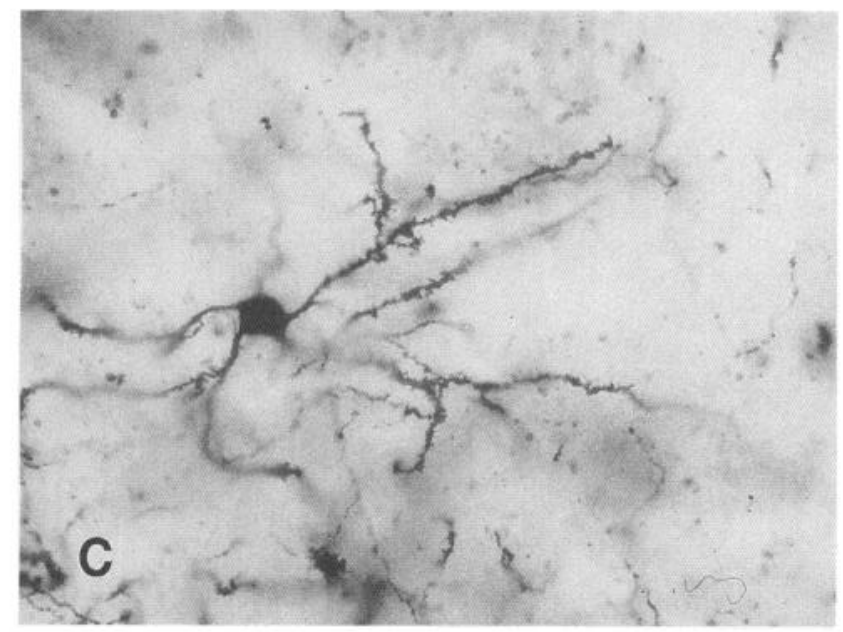

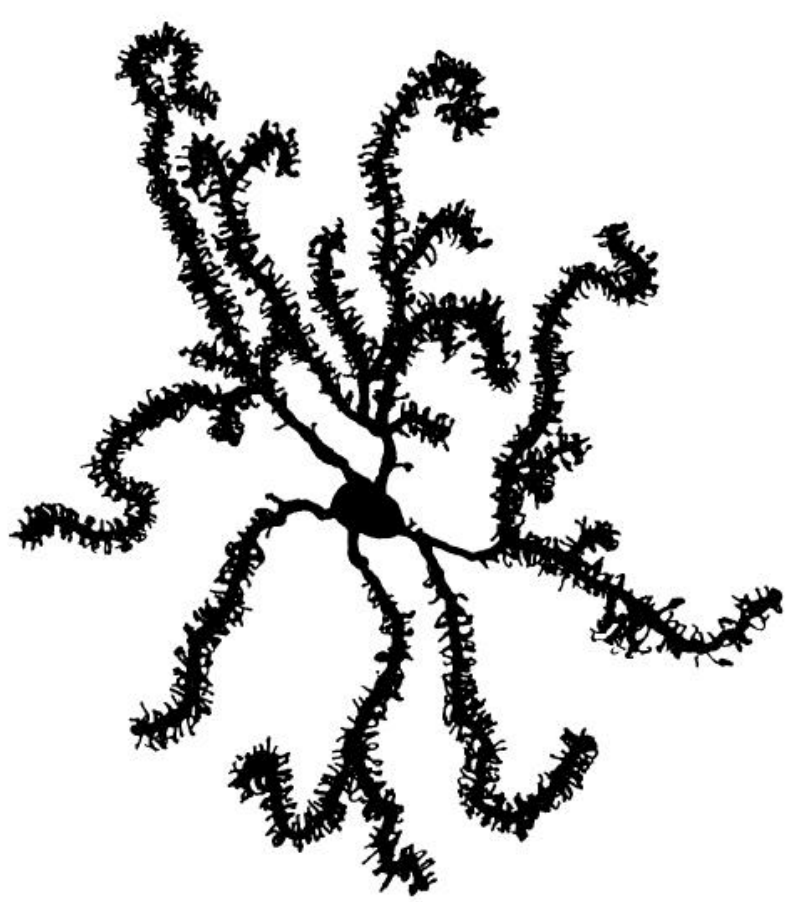

B

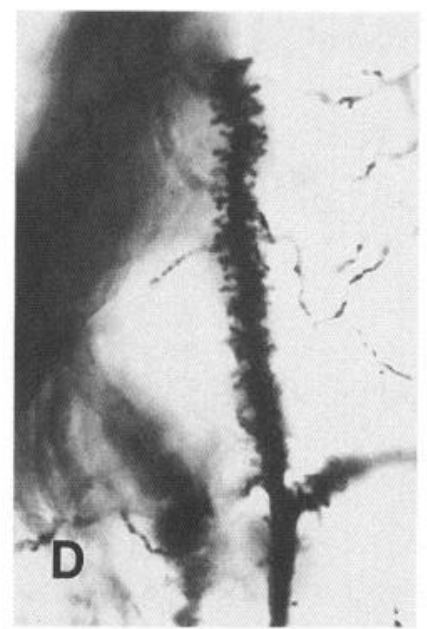

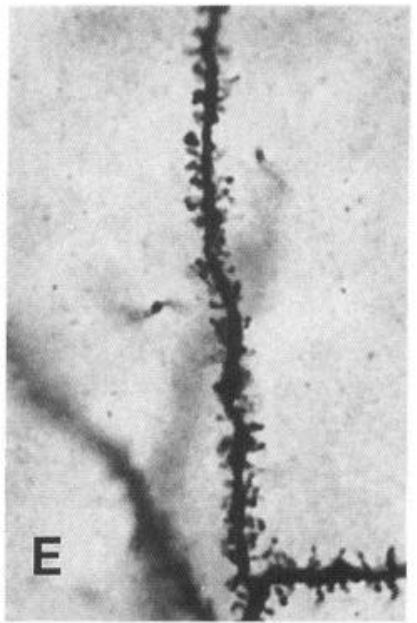

Figure 10. Camera lucida drawings of spiny striatal neuron from a chronic 3-NP-treated animal in $B$ and normal control in $A$. Morphologic alterations of spiny striatal neurons in the 3-NP-treated animals consist of recurving dendritic segments $(A)$, short-segment branching $(C)$, and marked increases in spine density with abnormal dendritic growth $(D)$ as compared to the normal $(E)$.

in spiny striatal neurons in HD were present within the caudate putamen of the chronic 3-NP-treated animals. These alterations were characterized by changes in the dendritic branching pattern and recurving of dendrites (Fig. 10A,B). As compared to the saline-treated animals there was short-segment branching along dendrites, with increased dendritic spine density and thickness of dendrites (Fig. 10C-E). Immunocytochemistry for NCAM, a marker for neurite outgrowth, was increased in and around the lesion site. It was found in both neurons and immunoreactive puncta within the neuropil (Fig. 11).

\section{Discussion}

In the present study we examined whether either intrastriatal or systemic administration of the known mitochondrial toxin 3 -NP could induce excitotoxic neuronal death in rats. $3-\mathrm{NP}$ is a plant- and fungal-derived neurotoxin that is an irreversible inhibitor of succinate dehydrogenase (Alston et al., 1977; Coles et al., 1979). Ingestion of 3-NP has been linked to toxicity in both livestock and in human (Ludolph et al., 1991). Chronic poisoning in livestock leads to labored respiration, generalized 

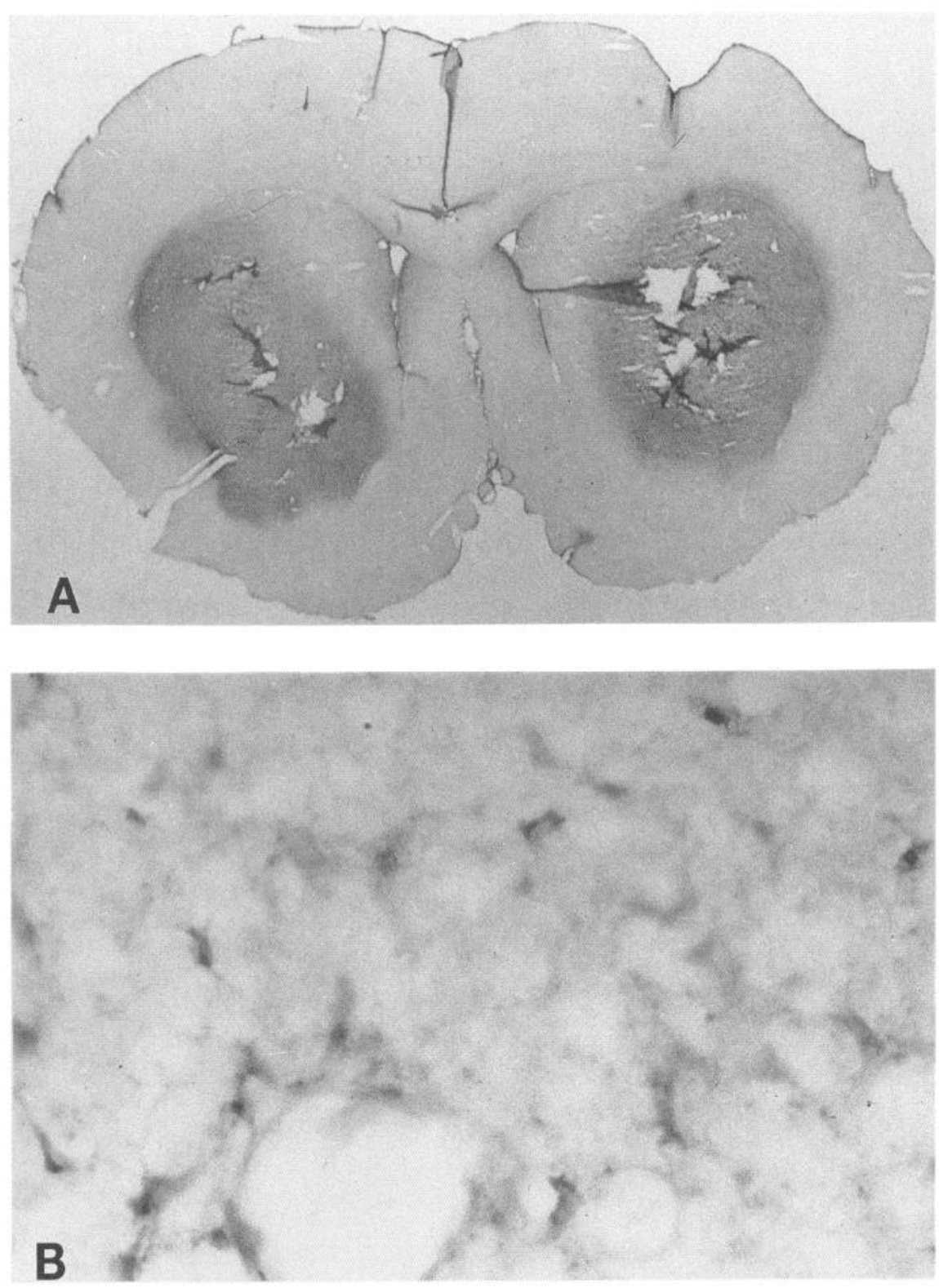

Figure 11. Immunocytochemical staining for NCAM in chronic 3-NPtreated rat. On gross inspection $(A)$, intense immunoreactivity is observed throughout the caudate putamen and is present in both neurons and immunoreactive puncta within the neuropil $(B)$. weakness, abnormal gait, and hind limb paralysis. Exposure in human has occurred in China where children have ingested sugar cane contaminated with the fungus Arthrinium (Ludolph et al., 1991). The clinical picture consists of an acute encephalopathy followed by appearance of a delayed onset dystonia 11-60 d after ingestion. The patients experience torsion spasms, torticollis, facial grimacing, and jerk-like movements. CT scans show bilateral hypodensities in the putamen and to a lesser extent the globus pallidus. It is of interest that a similar distribution of lesions has been seen in human following cyanide overdoses (Uitti et al., 1985; Carella et al., 1988; Rosenberg et al., 1989).

We characterized both the neurochemical features and the neuronal specificity of striatal lesions induced with 3-NP. Intrastriatal injections of 3-NP resulted in dose-dependent significant reductions in markers for both striatal intrinsic neurons such as GABA, SPLI, SLI, and NPYLI, as well as a reduction in markers for striatal afferents such as dopamine and its me- tabolites. The effect on dopamine is consistent with those we have found after intrastriatal injections of aminooxyacetic acid, manganese, and 1-methyl-4-phenylpyridinium (Beal et al., 1991; Storey et al., 1992; Brouillet et al., 1993), which also impair mitochondrial energy metabolism. In contrast, systemic administration of 3-NP spared dopamine concentrations and resulted in increased concentrations of DOPAC and HVA, consistent with increased dopamine turnover. Subacute systemic administration of 3-NP resulted in a pattern of neuronal selectivity similar to that seen following intrastriatal injection, with decreases in GABA, substance P, somatostatin, and neuropeptide $\mathrm{Y}$. These lesions showed a marked age dependence, with 4-month-old animals being much more vulnerable than 1-monthold animals. This is consistent with observations we have made studying the age dependence of intrastriatal injections of 3-NP (Brouillet et al., 1993).

Following local intrastriatal injection, both the freeze-clamp technique and death by focused microwave irradiation showed 
significant reductions in ATP and increases in lactate. These observations were also confirmed in real time using water-suppressed proton chemical shift magnetic resonance imaging. At $3 \mathrm{hr}$ following 3-NP injections localized accumulations of lactate were seen in the striatum. Similarly, following systemic administration of 3-NP for $3 \mathrm{~d}$ localized accumulations of lactate were found in the striata, but not in other brain regions. The increases in lactate preceded the observation of lesions on $T_{2}$-weighted images. Subsequent imaging of the lesions using $T_{2}$-weighted magnetic resonance imaging showed focal increases in signal in the striatum, similar to observations made in human following a cyanide overdose (Rosenberg et al., 1989).

Histologic examination of the lesions showed dose-dependent striatal lesions characterized by neuronal loss and extensive gliosis. A similar pattern of neuronal loss was seen after either intrastriatal or subacute systemic administration of 3-NP. There was a comparable loss of spiny neurons stained with $\mathrm{CaBP}$ and medium-sized aspiny neurons containing somatostatin and NADPH-diaphorase. There was some sparing of large neurons within the lesioned area. The lesions following systemic administration of 3-NP preferentially affected the striatum. With the smaller lesions there was no gliosis or neuronal loss abservable in other brain regions, although with very large lesions neuronal loss and gliosis was observed in the hippocampus and cerebral cortex.

The neurochemical and histologic features of the intrastriatal and subacute systemic 3-NP lesions were similar to those we found with striatal lesions produced by non-NMDA agonists such as kainate and AMPA (Beal et al., 1989). There was a comparable loss of markers for both spiny neurons (GABA, SPLI, CaBP) and medium-sized aspiny neurons (SLI, NPYLI, somatostatin, NADPH-diaphorase). Prior decortication, which removes the corticostriatal glutamatergic input, attenuated the lesions, consistent with reports that prior decortication blocks kainic acid striatal lesions (McGeer et al., 1978; Biziere and Coyle, 1979). The effects of decortication on dopamine depletion following local 3-NP injection were only partial, consistent with findings following intrastriatal injection of either aminooxyacetic acid or 1-methyl-4-phenylpyridinium (Storey et al., 1992; M. F. Beal, unpublished observations). Striatal lesions produced by local intrastriatal injection of 3-NP were not blocked by MK-801, using a paradigm that is effective in blocking lesions produced by 1-methyl-4-phenylpyridinium (Storey et al., 1992), consistent with activation of non-NMDA receptors. These results are consistent with a recent report showing that although MK-801 conferred some protection against 3-NP neurotoxicity in cortical explants, more robust protection was obtained by a combination of MK-801 and the non-NMDA antagonist 6-cyano-7-nitroquinoxaline-2,3-dione (CNQX) (Ludolph et al., 1992).

The present studies are consistent with earlier observations of Gould and Gustine (1982). They found that systemic administration of 3-NP to mice resulted in swollen mitochondria and a reduction of brain mitochondrial succinate dehydrogenase activity to $20 \%$ of control values. Electron microscopy showed marked swelling of neuronal processes and cell bodies, similar to observations made following excitotoxic lesions. Hamilton and Gould $(1987 \mathrm{a}, \mathrm{b})$ hypothesized that 3 -NP produced lesions by inducing histotoxic hypoxia, since in their studies systemically administered 3-NP induced increased arterial blood pressure and arterial blood oxygen as compared with controls. In contrast, prior reports of cyanide intoxication had considered it necessary to induce systemic hypotension to produce brain lesions (Brierley et al., 1976, 1977). Our results, showing that intrastriatal injection of 3-NP produces lesions, suggest that histotoxic hypoxia in the absence of systemic hypotension is sufficient to produce nerve cell death.

We observed similar behavioral observations to those reported by Hamilton and Gould (1987a). Following subacute intraperitoneal systemic administration of 3-NP, rats showed transient lethargy after the second or third dose. They then developed mild incoordination and stiffness of their hind limbs. At the most advanced stage the hind limbs were rigidly extended and rats were recumbent on their sides or stomach. With time, animals that survived showed variable recovery and some rats were able to resume walking, yet remained wobbly. Since lesions were not observed in either the spinal cord or other brain regions, it appears that the motor symptoms represent a striatal-induced dystonia.

The possibility that impairment of energy metabolism might result in secondary excitotoxic lesions was first proposed by Henneberry and associates (Novelli et al., 1988). They hypothesized that a depletion of energy stores may lead to relief of the voltage-dependent $\mathbf{M g}^{2}$ । block of the NMDA receptor, leading to persistent receptor activation. Zeevalk and Nicklas (1990) found that partial inhibition of energy metabolism with either iodoacetate or cyanide alone resulted in NMDA receptor-dependent neuronal lesions, which were not accompanied by increases in extracellular glutamate. With increasing intensity or duration of metabolic stress there was activation of non-NMDA receptors as well, as indicated by the observation that the addition of the non-NMDA antagonist CNQX in combination with MK-801 produced a greater protection than when either antagonist was given alone (Zeevalk and Nicklas, 1991). Furthermore, they showed that graded titration of membrane potential with potassium or relief of the $\mathrm{Mg}^{2+}$ block of the NMDA receptor mimicked the effects of metabolic inhibition (Zeevalk and Nicklas, 1992).

We believe that our results with 3-NP in vivo are consistent with these results. Microdialysis studies showed that a single dose of 3-NP does not result in increased glutamate concentrations for at least $5 \mathrm{hr}$ after systemic administration, a time point $(4 \mathrm{hr})$ at which we found a twofold increase in striatal lactate concentrations. These results are therefore consistent with a postsynaptic mechanism by which energy depletion results in neurons becoming vulnerable to endogenous concentrations of glutamate. Previous work showed that 3-NP has no direct depolarizing effects in hippocampal slices (Riepe et al., 1992). Consistent with our observations, Ludolph et al. (1992) found that 3-NP produces energy depletion and neuronal degeneration in cortical explants that was attenuated by pretreatment with glutamate antagonists.

Both intrastriatal and subacute administration of 3-NP are likely to produce profound energy deficits within the cell, since 3-NP irreversibly halts both the Krebs cycle and complex II activity. We reasoned, however, that a chronic low-grade administration of 3-NP might produce a less severe metabolic compromise resulting in partial neuronal depolarization and selective activation of NMDA receptors. We therefore administered 3-NP at a dose of $12 \mathrm{mg} / \mathrm{kg}$ for 1 month by Alzet pump. Animals that received 3-NP using this paradigm showed variable susceptibility, with only half the animals surviving for the entire month. In these animals there were selective striatal lesions characterized by neuronal loss and astroglial proliferation, 


\section{Table 2. Comparison of Huntington's disease and 3-Nitropropionic acid striatal lesions}

Huntington's disease

Young adult onset

Striatal vulnerability

Movement disorder chorea

Sparing of striatal afferents

Loss of spiny projection neurons

Spiny neuron dendritic abnormalities

Sparing of NADPH-diaphorase neurons
3-Nitropropionic acid

Vulnerability of young adult animals

Striatal vulnerability

Movement disorder dystonia

Sparing of striatal afferents

Loss of spiny projection neurons

Spiny neuron dendritic abnormalities

Sparing of NADPH-diaphorase neurons with no evidence of pathology elsewhere in the brain. In two of the animals the lesions were not apparent on Nissl stains, but neuronal depletion was confirmed with quantitative cell counts. The lesions showed selective sparing of both NADPH-diaphorase and large neurons (presumed cholinergic) as compared with Nissl- and CaBP-stained neurons. This is a pattern we previously found is associated with NMDA excitotoxic lesions (Beal et al., 1986a, 1989). In addition, we found that this paradigm produces proliferative dendritic changes in striatal spiny neurons that closely resemble those seen in HD (Ferrante et al., 1991; Brouillet et al., 1993). Although some increases in spiny dendrites occur with normal aging (Rafols et al., 1989), they are not as marked as those observed in the present study. In the present study we also show that these lesions result in the induction of other growth-related markers such as NCAM. Both intrastriatal and systemic administration of 3-NP appear to cause striatal lesions by a secondary excitotoxic mechanism due to compromised energy production. In the case of intrastriatal or subacute administration there is severe tissue ischemia with glutamate release and activation of non-NMDA receptors, whereas mild metabolic compromise by chronic administration leads to selective NMDA receptor activation by postsynaptic mechanisms.

The present results have implications for the pathogenesis of striatal degeneration associated with both known mitochondrial defects and neurodegenerative diseases. Symmetric basal ganglia lesions are found in patients with defects in succinate oxidation, in Leigh's disease, and in some families with Leber's optic atrophy (Martin et al., 1988; Fujii et al., 1990; Bruyn et al., 199 1; Larsson et al., 1991). Chronic systemic administration of 3-NP also produces lesions that share many of the characteristic histologic and neurochemical features of HD as summarized in Table 2 . We have recently obtained evidence of impaired oxidative metabolism in HD using proton chemical shift magnetic resonance imaging (Koroshetz et al., 1992). Chronic 3-NP lesions appear to be an improved model of HD pathology and may prove useful in evaluating potential therapies for IID.

\section{References}

Albin RL, Greenamyre JT (1992) Alternative excitotoxic hypothesis. Neurology 42:733-738.

Alston TA, Mela L, Bright HF (1977) 3-nitropropionate, the toxic substance of Indigofera, is a suicide inactivator of succinate dehydrogenase. Proc Natl Acad Sci USA 74:3767-3771.

Arnold MA, Reppert SM, Rorstad O, Sagar SM, Keutmann HT, Perlow MJ, Martin JB (1982) Temporal patterns of somatostatin immunoreactivity in the cerebrospinal fluid of rhesus monkeys: effect of environmental lighting. J Neurosci 2:674-680.

Beal MF (1992) Does impairment of energy metabolism result in excitotoxic neuronal death in neurodegenerative illnesses? Ann Neurol 31:119-130.

Beal MF, Mazurek MF (1987) Substance P-like immunoreactivity is reduced in Alzheimer's disease cerebral cortex. Neurology 37:12051209.

Beal MF, Kowall NW, Ellison DW, Mazurek MF, Swartz KJ, Martin JB (1986a) Replication of the neurochemical characteristics of Huntington's disease by quinolinic acid. Nature 321:168-171.

Beal MF, Mazurek MF, Lorenz LJ, Chattha GK, Ellison DW, Martin JB (1986b) An examination of ncuropeptide Y postmortem stability in an animal model stimulating human autopsy conditions. Neurosci Lett 64:69-74.

Beal MF, Kowall NW, Swartz KJ, Ferrante RJ, Martin JB (1989) Differential sparing of somatostatin-neuropeptide $Y$ and cholinergic neurons following striatal excitotoxin lesions. Synapse 31:38-47.

Beal MF, Matson WR, Swartz KJ, Gamache P, Bird ED (1990) Multicomponent analysis of tryptophan and tyrosine metabolism in Huntington's disease: evidence for reduced formation of kynurenic acid. J Neurochem 55:1327-1339.

Beal MF, Swartz KJ, Hyman BT, Storey E, Finn SF, Koroshetz W (1991) Aminooxyacetic acid results in excitotoxin lesions by a novel indirect mechanism. J Neurochem 57:1068-1073.

Biziere K, Coyle JT (1979) Effects of cortical ablation on the neurotoxicity and receptor binding of kainic acid in striatum. J Ncurosci Res 4:383-398.

Bohlen P, Stein S, Dairman W, Udenfriend S (1973) Fluorometric assay of proteins in the nanogram range. Arch Biochem Biophys 155: 213-220.

Brierley JB, Brown AW, Calverly J (1976) Cyanide intoxication in the rat: physiological and neuropathological aspects. J Neurol Neurosurg Psychiatry 39:129-140.

Brierley JB, Prior PF, Calverly J, Brown AW (1977) Cyanide intoxication in Macaca mulatta: physiological and neuropathological aspects. J Neurol Sci 31:133-157.

Brouillet E, Jenkins BG, Hyman BT, Ferrante RJ, Kowall NW, Srivastava R, Samanta Roy D, Rosen BR, Beal MF (1993) Age-dependent vulnerability of the striatum to the mitochondrial toxin 3-nitropropionic acid. J Neurochem 60:356-359.

Bruyn GW, Vielvoye GJ, Went LN (1991) Hereditary spastic dystonia: a new mitochondrial encephalopathy? J Neurol Sci 103:195-202.

Carella F, Grassi M, Savoiardo M, Contri P, Rapuzzi B, Mangoni A (1988) Dystonic-Parkinsonism syndrome after cyanide poisoning: clinical and MRI findings. J Neurol Neurosurg Psychiatry 51:13451348.

Choi DW (1988) Glutamate neurotoxicity and diseases of the nervous system. Neuron 1:623-634.

Coles CJ, Edmondson DE, Singer TP (1979) Inactivation of succinate dehydrogenase by 3-nitropropionate. J Biol Chem 254:5161-5167.

Dure LS, Young AB, Penney AB (1991) Excitatory amino acid binding sites in the caudate nucleus and frontal cortex of Huntington's disease. Ann Neurol 30:785-793.

Ellison DW, Beal MF, Martin JB (1987) Amino acid neurotransmitters in postmortem human brain analyzed by high performance liquid chromatography with electrochemical detection. J Neurosci Methods 19:305-315.

Ferrante RJ, Kowall NW, Richardson EP Jr (1991) Proliferative and degenerative changes in striatal spiny neurons in Huntington's disease: a combined study using the section-Golgi method and calbindin $\mathrm{D}_{28} \mathrm{~K}$ immunocytochemistry. J Neurosci 11:3877-3887. 
Ferrante RJ, Kowall NW, Cipolloni PB, Storey E, Beal MF (1993) Excitotoxin lesions in primates as a model for Huntington's disease: histopathologic and neurochemical characterization. Exp Neurol 119: 46-71.

Fujii T, Ito M, Okuno T, Mutoh K, Nishikomori R, Mikawa H (1990) Complex I (reduced nicotinamide adenine dinucleotide-coenzyme Q reductase) deficiency in two patients with probable Leigh syndrome. J Pediatr 116:84-87.

Gould DH, Gustine DL (1982) Basal ganglia degeneration, myelin alterations, and enzyme inhibition in mice by the plant toxin 3-nitropropanoic acid. Neuropathol Appl Neurobiol 8:377-393.

Hamilton BF, Gould DH (1987a) Nature and distribution of brain lesions in rats intoxicated with 3-nitropropionic acid: a type of hypoxic (energy deficient) brain damage. Acta Neuropathol (Berl) 72 : 286-297.

Hamilton BF, Gould DH (1987b) Correlation of morphologic brain lcsions with physiologic alterations and blood-brain barrier impairment in 3-nitropropionic acid toxicity in rats. Acta Neuropathol (Berl) 74:67-74.

Jenkins BG, Storey E, Beal MF, Rusen BR (1991) Chemical shift imaging of focal neurochemical lesions in rats brains. Proc Soc Magn Reson Med 1:437.

Koroshetz WJ, Jenkins BG, Beal MF, Kosen BR (1992) Localized proton-NMR spectroscopy in patients with Huntington's disease (HD) demonstrates abnormal lactate levels in occipital cortex: evidence for compromised metabolism in HD. Neurology 42:319.

Larsson N-G, Andersen O, Holme E, Oldfors A, Wahlstrom J (1991) Leber's hereditary optic neuropathy and complex I deficiency in muscle. Ann Neurol 30:701-708.

Ludolph AC, He F, Spencer PS, Hammerstad J, Sabri M (1991) 3Nitropropionic acid - exogenous animal neurotoxin and possible human striatal toxin. Can J Neurol Sci 18:492-498.

Ludolph AC, Seelig MO, Ludolph A, Novitt P, Allen CN, Spencer PS, Sabri MI (1992) 3-Nitropropionic acid decreases cellular energy levels and causes neuronal degeneration in cortical explants. Neurodegeneration 1:21-28.

Lust WD, Feussner GK, Barbehenn EK, Passoneau JV (1981) The enzymatic measurements of adenine nucleotides and P-creatinine in picomole amounts. Anal Biochem 110:258-266.

Martin JJ, Van de Vyver FL, Scholte HR, Roodhooft AM, Ceuterick
C, Martin L, Luyt-Houwen IEM (1988) Defect in succinate oxidation by isolated muscle mitochondria in a patient with symmetrical lesions in the basal ganglia. J Neurol Sci 84:189-200.

McGeer EG, McGeer PL, Singh K (1978) Kainate-induced degeneration of neostriatal neurons: dependency upon corticostriatal tract. Brain Res 139:381-383.

Novelli A, Reilly JA, Lysko PG, Henneberry RC (1988) Glutamate becomes neurotoxic via the $N$-methyl-D-aspartate receptor when intracellular energy levels are reduced. Brain Res 451:205-212.

Rafols JA, Cheng HW, McNeill TH (1989) Golgi study of the mouse striatum: age-related dendritic changes in different neuronal populations. J Comp Neurol 279:212-227.

Riepe M, Hori N, Ludolph AC, Carpenter DO, Spencer PS, Allen CN (1992) Inhibition of energy metabolism by 3-nitropropionic acid activates ATP-sensitive potassium channels. Brain Res 586:61-62.

Rosenberg NL, Myers JA, Wayne Martin WR (1989) Cyanide-induced parkinsonism: clinical, MRI, and 6-fluorodopa PET studies. Neurology 39:142-144.

Schon R (1965) A simple and sensitive enzymatic method for the determinations of L-lactic acid. Anal Biochem 12:413-418.

Storey E, Hyman BT, Jenkins B, Brouillet E, Miller JM, Rosen BR, Beal MF (1992) 1-Methyl-4-phenylpyridinium produces excitotoxic lesions in rat striatum as a result of impairment of oxidative metabolism. J Neurochem 58:1975-1978.

Uitti RJ, Rajput AH, Ashenhurst EM, Rozdilsky B (1985) Cyanideinduced parkinsonism: a clinicopathologic report. Neurology 35:921925.

Young AB, Greenamyre JT, Hollingsworth Z, Albin R, D'Amato C, Shoulson I, Penney JB (1988) NMDA receptor losses in putamen from patients with Huntington's disease. Science 241:981-983.

Zeevalk GD, Nicklas WJ (1990) Chemically induced hypoglycemia and anoxia: relationship to glutamate receptor-mediated toxicity in retina. J Pharmacol Exp Ther 253:1285-1292.

Zeevalk GD, Nicklas WJ (1991) Mechanisms underlying initiation of excitotoxicity associated with metabolic inhibition. J Pharmacol Exp Ther 257:870-878.

Zeevalk GD, Nicklas WJ (1992) Evidence that the loss of the voltagedependent $\mathrm{Mg}^{2+}$ block at the $N$-methyl-D-aspartate receptor underlies receptor activation during inhibition of neuronal metabolism. J Pharmacol Exp Ther 59:1211-1220. 